\title{
The influence of the support on the singlet oxygen quantum yields of porphyrin supported photosensitizers
}

\author{
Marta Pineiro, Sónia M. Ribeiro, and Arménio C. Serra* \\ Departamento de Química, Universidade de Coimbra, 3049-535, Coimbra, Portugal \\ E-mail: armenio.serra@gmail.com
}

Dedicated to Professor António M. d'A. Rocha Gonsalves on his 70 ${ }^{\text {th }}$ birthday and especially for the many years of commitment to teaching and the pursuance of research in organic chemistry

\begin{abstract}
A halogenated porphyrin was covalently supported on aminoalkylated silica and aminoalkylated Merrifield polymer through a chlorosulfonation reaction. The supported porphyrin was tested for the photoxidation of $\alpha$-terpinene. The kinetics of photocatalysis were evaluated using 9,10-dimethylanthracene as target and singlet oxygen formation quantum yield was calculated. The influence of the support, silica, Merrifield and other polymers, on the quenching of singlet oxygen were also evaluated.
\end{abstract}

Keywords: Photooxidation, supported catalysts, porphyrins, polymer, singlet oxygen

\section{Introduction}

Singlet oxygen mediated oxidations are very attractive reactions which make use of clean, accessible and economical reaction conditions. ${ }^{1,2}$ They can give products which can hardly be obtained by other methods, for example endoperoxides ${ }^{3,4}$ and allylic hydroperoxides. $^{5,6}$ The need for a photosensitizer molecule to transfer energy through oxygen to organic molecules, which sometimes have low stability and thus that must be separated from the products, can be viewed as a limitation of the process. A way to avoid this is the use of supported photosensitizers: some useful and practical solutions have already being described in the literature. ${ }^{7-10}$ However, supported photosensitizers also have weaknesses that affect the performance of the oxidation reaction such as: (1) leaching the photosensitizers into the solution phase if sensitive bonds exist between the support and photosensitizer, (2) diminished activity of the photosensensitizer when attached to a support and (3) the accessibility of oxygen or substrates to photosensitizers 
can be affected by the support structure. Another important factor that can limit the action of supported photosensitizers is the possibility of fast quenching of the generated singlet oxygen by the support structure due to the presence and proximity of quenching groups. Porphyrins are good photosensitizers to generate singlet oxygen due to their photochemical characteristics and stability in reaction media. ${ }^{11}$ A porphyrin macrocycle can incorporate several functional groups that can modulate solubility properties and thus it is possible to carry out reactions in different solvents. Particularly important is the efficiency of porphyrins to generate singlet oxygen due to the heavy atom effect ${ }^{12}$ as well as their stability in reaction media. ${ }^{13}$

In this work we present the synthesis of new supported photosensitizers (SPS) based on chlorinated porphyrins, and their efficiency as photooxidation catalysts. We also studied the ability of these SPS in generating singlet oxygen relative to free chlorinated porphyrins, highlighting the quenching effects caused by the support that can influence the efficiency of these supported catalysts.

\section{Results and Discussion}

In our recent studies, we developed a straightforward method for supporting chlorinated porphyrins on a modified Merrifield polymer using different lengths of spacers between porphyrin and polymer backbone. ${ }^{10}$ It was concluded that the Merrifield supported photosensitizers with a $\mathrm{C}_{12}$-chain spacer SPS-1 showed better efficiency than those with a $\mathrm{C}_{6}$-chain spacer SPS-2 possibly because the photosensitizer experiences a more homogeneous environment, Chart $1 .^{10,14}$

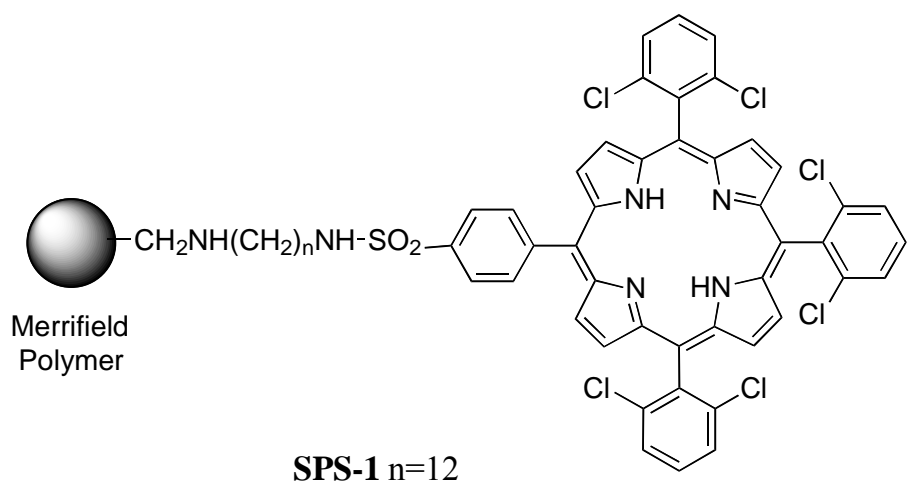

SPS-2 $n=6$

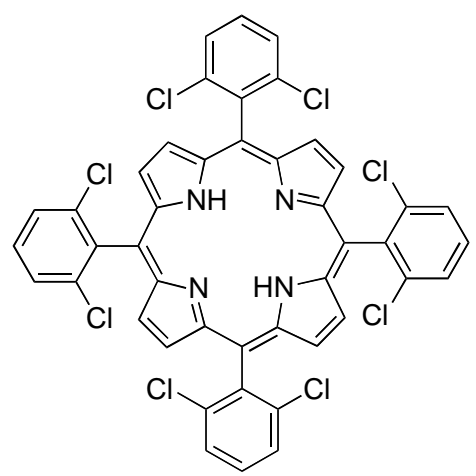

$\mathrm{TDCPPH}_{2}$

\section{Chart 1}


In the present study, we extended the aforementioned strategy and prepared a supported catalyst containing a halogenated porphyrin covalently bonded to silica through a long $\mathrm{C}_{12}$ carbon chain, SPS-3, Scheme 1.

Support preparation

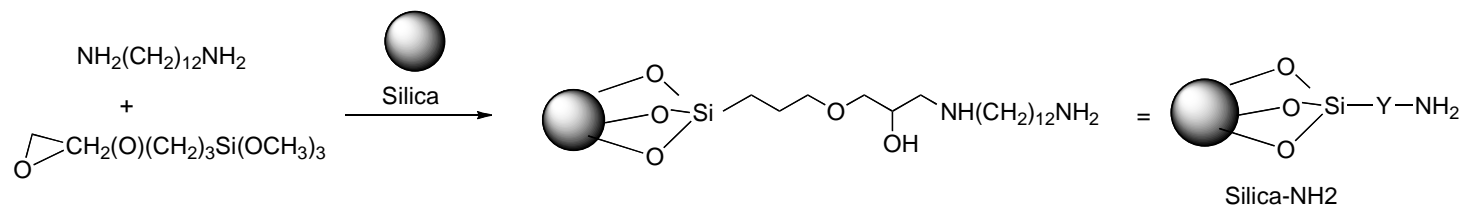

Photocatalyst preparation
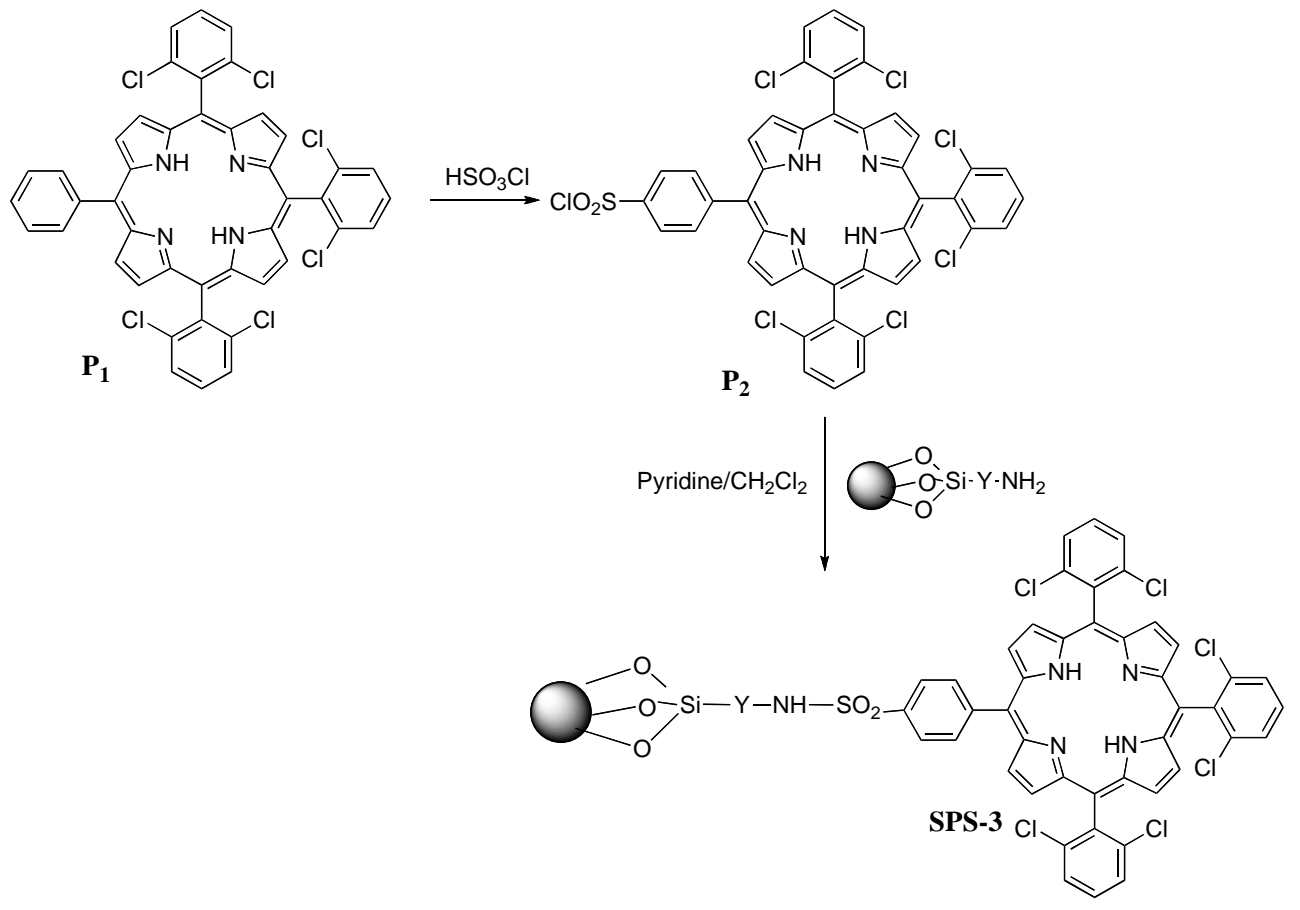

\section{Scheme 1}

The silica surface was modified by incorporation of amino groups (Silica- $\mathrm{NH}_{2}$ ) through a glycidyl bridge resulting from reaction between (3glycidyloxypropyl)trimethoxysilane, 1,12-dodecyldiamine and activated silica. ${ }^{15}$ The covalent linkage between the porphyrin and the amino groups of the modified silica was achieved by reaction with the chlorosulfonated porphyrin $\mathbf{P}_{2}$, which was easily obtained by chlorosulfonation of porphyrin $\mathbf{P}_{\mathbf{1}}$. The presence of porphyrin bonded to silica was confirmed by characteristics bands in the infrared spectra of SPS-3. In particularly, the weak bands at 1558 and $1429 \mathrm{~cm}^{-1}$ (for the free porphyrin, at 1557 and $1428 \mathrm{~cm}^{-1}$ respectively) can be assigned to the carbon-carbon double bond stretch and carbonhydrogen bending. ${ }^{16}$ 
Photocatalyst SPS-1 showed low values for loading of supported porphyrin $(0.040$ $\mathrm{mmol} / \mathrm{g}$ ). With the objective of preparing a catalyst with a higher loading, we followed the same procedure for supporting the chlorinated porphyrin but using a commercial Merrifield resin with higher initial loading of benzyl chloride groups. As expected, we obtained a supported photosensitizer SPS-4 (see experimental) with three times more supported porphyrin (loading of $0.11 \mathrm{mmol} / \mathrm{g}$ ). Following the same methodology the chlorosulfonated porphyrin $\mathbf{P}_{2}$ was reacted with commercial aminated polystyrene divinylbenzene copolymer (PSDV-NH 2 ) to obtain a supported photosensitizer with no spacer between the polymer and the porphyrin (SPS-5). All supported photosensitizers (SPS-1 to SPS-5) were tested in the photooxidation of $\alpha$-terpinene (1) to produce ascaridole (2) as major product and $p$-cymene (3) from $\alpha$-terpinene aromatization. For comparison purposes, the result of the photooxidation with the free porphyrin (TDCPPH $\mathbf{P}_{2}$ ) are also presented (Table 1).

Table 1. Results of photooxidation of $\alpha$-terpinene (1) with supported photosensitizers SPS-1 to SPS- $5^{\text {a }}$

\begin{tabular}{ccc}
\hline & SPS-1 to SPS-5 \\
\hline Photosensitizer & Reaction Time (h) & Yield of $2(\%)^{\mathrm{b}}$ \\
\hline TDCPPH & & $96(4)^{10}$ \\
SPS-1 & 2.3 & $91(9)^{10}$ \\
SPS-2 & 3.5 & $56(44)$ \\
SPS-3 & 11 & $74(26)$ \\
SPS-4 & 7.5 & $26(74)$ \\
SPS-5 & 35 & $65(35)$ \\
\hline
\end{tabular}

${ }^{\mathrm{a}}$ Catalyst/substrate molar ratio of $1 / 5000$.

${ }^{b}$ Determined by the NMR integration of the reaction mixture after removal of the polymer by filtration, and evaporation of solvent. The number in parentheses is the amount of $p$-cymene (3).

The results in Table 1 show that all the supported photosensitizers are less active than the free porphyrin. SPS-1, with the longer spacer between the porphyrin and the polymer structure, is the most active and selective supported photosensitizer. The absence of a spacer is not a favourable situation as indicated by the results obtained using SPS-5. On the other hand, the presence of a longer spacer alone is not sufficient to form an active catalyst. Silica supported porphyrin SPS-3, with a $\mathrm{C}_{12}$ spacer, does not give the same results as SPS-1 (which has the same spacer). This observation points to some influence 
of the support on catalyst efficiency. Moreover, a deactivating effect of the support is seen in the case of SPS-4 which, in spite of having a higher loading of porphyrin, is the least active catalyst.

In fact, supports give heterogeneity to the catalysts and help the catalyst recovery, for further use. However the support may interfere with the oxidation process particularly on the amount of ${ }^{1} \mathrm{O}_{2}$ generated. The incorporation of the photosensitizer on the support can bring some difficulties to the efficiency of the oxidation due to problems caused in ${ }^{1} \mathrm{O}_{2}$ photogeneration related to molecular distortions, ${ }^{17,18}$ dye aggregation ${ }^{19}$ or ${ }^{1} \mathrm{O}_{2}$ deactivation. ${ }^{20}$ To assess whether the support has any influence on singlet oxygen generation, singlet oxygen quantum yields for the different photocatalysts (SPS-1 to SPS5) were measured by steady state photolysis using dimethylanthracene (DMA) as target and $\mathbf{T D C P P H}_{2}$ as reference, comparing the slopes of the semilogarithmic plots of the decay of the absorption of the quencher at $380 \mathrm{~nm}$ with time $\left(\ln \left(\mathrm{A}_{0} / \mathrm{A}\right)\right.$ vs time) (Figure 1 ), with the corresponding slope obtained for the reference. The solutions were prepared with the same concentration of DMA and the same amount of porphyrins taking into account the particular loading of each supported photosensitizers. To validate our methodology, a set of two experiments using the $\mathbf{T D C P P H} \mathbf{P}_{2}$ as reference were carried out daily. The analysis of all the data obtained on different days gave good agreement (slope $\left.0.057 \pm 0.001, \mathrm{r}^{2}=0.992\right)$.

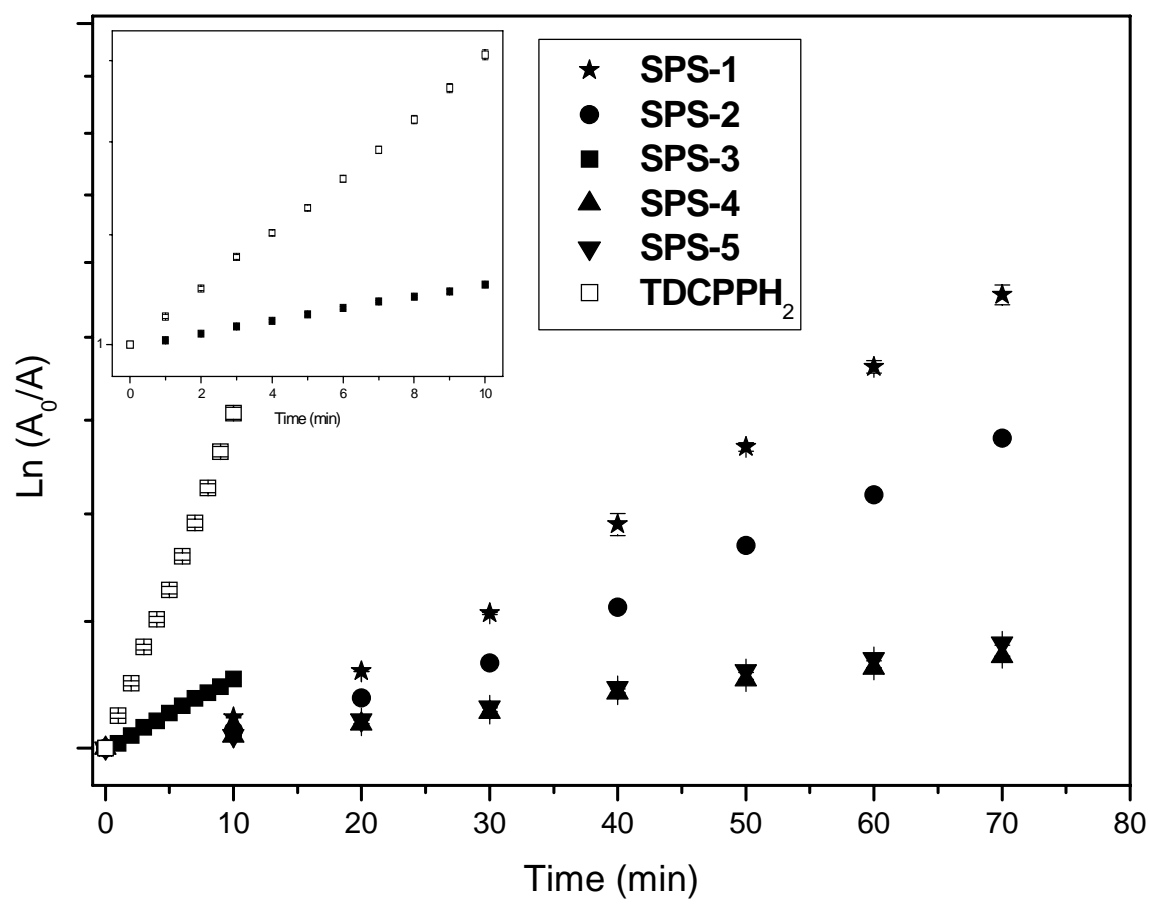

Figure 1. Semilogarithmic plots of DMA quenching using photocatalysts SPS-1 to SPS5. The zoom for SPS-3 and $\mathbf{T D C P P H}_{2}$ is depicted in the inset. 
Considering the first 10 minutes, the rate of quenching of DMA is higher for TDCPPH $_{2}$ and SPS-3 than for the other photocatalysts. Only in these two cases is the difference in the measured absorption of DMA sufficient to allow calculation of the rate constants. Extending the reaction time, significant differences were observed in the case of the other photocatalysts. The rate of DMA quenching using SPS-4 and SPS-5 could be obtained by linear fitting of the experimental data between 0 and 70 minutes. In the case of SPS-1 and SPS-2 the linear fit is not applicable to the complete reaction time, but clearly there are two different rates: in the first $30 \mathrm{~min}$, the reaction rate is slow (slopes of 0.006 and 0.004 for the respective liner fitting) and after that there is a significant increase of reaction rate (slopes of 0.016 and 0.010 for the respective linear fitting). This indicates that these Merrifield supported photosensitizers have an induction time of $c a$. 30 minutes that could be related to the wetting process (diffusion of the solvent with the dissolved oxygen and the DMA into the polymer). After this period of time, the efficiency of production of singlet oxygen increases. The singlet oxygen formation quantum yields are calculated using the slopes after 30 minutes for SPS-1 and SPS-2 and the slopes of the total reaction time for the other supported catalysts (Table 2).

Table 2. Singlet oxygen formation quantum yields of supported photocatalysts SPS-1 to SPS-5

\begin{tabular}{cc}
\hline $\begin{array}{c}\text { Supported } \\
\text { photosensitizer }\end{array}$ & $\Phi_{\Delta}$ \\
\hline SPS-1 & $0.27 \pm 0.02$ \\
SPS-2 & $0.16 \pm 0.01$ \\
SPS-3 & $0.17 \pm 0.01$ \\
SPS-4 & $0.03 \pm 0.01$ \\
SPS-5 & $0.04 \pm 0.01$ \\
\hline
\end{tabular}

All the supported photosensitizers present low yields for singlet oxygen formation and these values are significantly lower than the value for $\mathbf{T D C P P H}\left(\mathbf{P}_{\Delta}=1\right)$, ranging from 4 times less for SPS-1 to 30 times less for SPS-4. In a similar case, supported Rose Bengal on a poly(ethylene glycol) polymer presented a smaller decrease for the heterogeneous form relative to the homogeneous one ( 0.75 to 0.43 , respectively).$^{21}$ Thus, it seems reasonable to assume that in the present case the polymer has a great influence on singlet oxygen generation. An analysis of the results in Tables 1 and 2 shows that the values of $\Phi_{\Delta}$ for the supported photosensitizers correlated well with the kinetics observed for the photooxidation of $\alpha$-terpinene, the most efficient supported photosensitizers have the higher singlet oxygen quantum yields. Concerning the Merrifield supported photosensitizers, SPS-1 with the longer spacer has the highest $\Phi_{\Delta}$ and SPS 5 with no 
spacer between polymer and porphyrin has the lowest $\Phi_{\Delta}$ value. The result with SPS-4 confirms the low activity of this sensitizer in the photooxidation of $\alpha$-terpinene. Although having a $\mathrm{C}_{12}$ spacer SPS-4 is not able to generate singlet oxygen to then react with DMA. This polymer has the same spacer with SPS-1 and a significant increase in the porphyrin loading. As the porphyrin is the same, the reason for this sluggish activity can be related to quenching effects of formed singlet oxygen or the quenching of the triplet porphyrin state promoted by the proximity of porphyrin groups to the polymer surface. Porphyrin quenching effects by increasing the concentration are well known. ${ }^{22}$

Polymer structure has influence on the lifetime of ${ }^{1} \mathrm{O}_{2}$ if it is generated inside the polymer structure. This lifetime is considerably lower due to deactivation by the polymer structure particularly if a large amount of $\mathrm{C}-\mathrm{H}$ oscillators exists. ${ }^{23,24}$ In the present situation it is possible that, since the singlet oxygen is generated near the surface of the polymers, the polymer structure may also influence the deactivation processes. To evaluate if there is some effect of polymer structure on the singlet oxygen generation we carried out experiments to analyze the variation on $\Phi_{\Delta}$ of $\mathbf{T D C P P H}$ in the presence of the supports used. We also tested other materials that can be used as supports for photosensitizers like poly(ethyleneglycol), ${ }^{8}$ ion exchange resin, ${ }^{25}$ sulfonated polystyrene, ${ }^{26}$ chitosan, ${ }^{27}$ poly(ethyleneimine) and a Merrifield polymer linked to a 4,4'diaminobibenzyl spacer. Solutions of DMA and $\mathbf{T D C P P H} \mathbf{H}_{2}$ were prepared in the same concentration that the solution used as reference and $1 \mathrm{mg}$ of polymers or modified polymers were added. From the same plot as shown in Figure 1 the $\Phi_{\Delta}$ values were calculated (Table 3).

Table 3. Values for singlet oxygen quantum yields for $\mathbf{T D C P P H} \mathbf{H}_{2}$ in the presence of 1 $\mathrm{mg}$ of different supports

\begin{tabular}{|c|c|}
\hline Added support & $\Phi_{\Delta}$ \\
\hline Merrifield & $0.96 \pm 0.07$ \\
\hline Merrifield- $\mathrm{C}_{12}{ }^{\mathrm{a}}$ & $0.95 \pm 0.07$ \\
\hline Merrifield diaminobibenzyl $l^{\mathrm{b}}$ & $0.66 \pm 0.05$ \\
\hline Merrifield $\mathrm{HL}^{\mathrm{c}}$ & $0.95 \pm 0.07$ \\
\hline $\mathrm{PSDV}-\mathrm{NH}_{2}{ }^{\mathrm{d}}$ & $0.94 \pm 0.07$ \\
\hline Silica & $0.80 \pm 0.06$ \\
\hline Silica- $\mathrm{NH}_{2}{ }^{\mathrm{e}}$ & $0.84 \pm 0.06$ \\
\hline Poly(ethyleneimine $)^{\mathrm{f}}$ & $0.21 \pm 0.02$ \\
\hline Poly(ethyleneglycol) ${ }^{\mathrm{g}}$ & $0.91 \pm 0.07$ \\
\hline Amberlite $^{\circledR}$ IRA $400^{\mathrm{h}}$ & $0.95 \pm 0.07$ \\
\hline
\end{tabular}


Table 3. Continued

\begin{tabular}{cc}
\hline Added support & $\Phi_{\Delta}$ \\
\hline Sulfonated polystyrene $^{\mathrm{i}}$ & $0.94 \pm 0.07$ \\
Chitosan $^{\mathrm{j}}$ & $0.86 \pm 0.06$ \\
\hline
\end{tabular}

a amino alkylated Merrifield polymer with a $\mathrm{C}_{12}$ chain spacer. ${ }^{\mathrm{b}}$ amino alkylated Merrifield polymer with a 4,4' -diaminobiphenyl spacer (see experimental). 'amino alkylated Merrifield polymer with a $\mathrm{C}_{12}$ chain spacer with higher loading of aminoalkyl groups. ${ }^{\mathrm{d}}$ Poly(styrene co-divinylbenzene)aminomethylated. ${ }^{\mathrm{e}}$ aminoalkylated silica (see Scheme 1). ${ }^{\mathrm{f}}$ Poly(ethyleneimine) $\mathrm{M}_{\mathrm{n}}-600$. ${ }^{\mathrm{g}}$ poly(ethyleneglycol)methyl ether 2000. $\mathrm{h}_{\text {ionic }}$ exchange resin Amberlite ${ }^{\circledR}$ IRA 400200 mesh. i poly(sodium 4-styrene-sulfonate) type $\mathrm{M}_{\mathrm{w}}-70,000 .{ }^{\mathrm{j}}$ low molecular weight, $75-85 \%$ deacetylated.

The singlet oxygen quantum yield formation of $\mathbf{T D C P P H}_{2}$ in the presence of Merrifield, Merrifield- $\mathrm{C}_{12}$ or PSDV-NH 2 is the same, within the error interval, as for TDCPPH $_{2}$ in the absence of the support. In the case of silica and silica linked to the spacer $\mathrm{C}_{12}$ there is a small decrease of the singlet oxygen quantum yield that can be attributed to a quenching due to the $\mathrm{OH}$ groups in the silica. ${ }^{28}$ Chitosan also acts as a quencher to singlet oxygen. Poly(ethyleneimine), although having a great number of amino groups, is not a suitable support for these photosensitizers since it acts as a strong quencher of singlet oxygen. The reason may be related to the fact that it forms a homogeneous solution and the great quenching ability of amino groups. ${ }^{29}$ The influence of the nature of the spacer could be evaluated by comparing the quantum yields of the Merrifield with the biphenyl groups and Merrifield- $\mathrm{C}_{12}$; the presence of aromatic groups in the spacer decreases the quantum yield making them undesirable as supports in photooxidation reactions. The influence of the amount of support could be significant when considering higher quantities of polymer to be used. For example, in the case of Merrifield polymers that do not affect the singlet oxygen formation (Table 3 ) we verified a decrease of the singlet oxygen quantum yield from 0.96 to 0.83 when the amount of polymer was increased from $1 \mathrm{mg}$ to $5 \mathrm{mg}$.

\section{Conclusions}

Halogenated porphyrins can be covalently linked to aminoalkylated silica or aminoalkylated Merrifield polymer through a chlorosulfonation/amidation reaction. The supported porphyrins were tested in the photoxidation of $\alpha$-terpinene and the results correlated with the singlet oxygen formation quantum yields. Increasing the loading of the porphyrin incorporation does not increase the catalytic efficiency or the singlet 
oxygen quantum yield. With $\mathbf{T D C P P H}_{2}$ as photosensitizer, quenching of singlet oxygen by some heterogeneous supports were observed.

\section{Experimental Section}

General Procedures. All solvents were purified before use according to the literature procedures. $^{30} \quad \alpha$-Terpinene, 1,12-diaminododecane, 1,6-diaminohexane, (3glycidyloxypropyl)-trimethoxysilane, 9,10-dimethylantracene(DMA), aminomethylated polystyrene divinylbenzene copolymer, Merrifield's peptide resins (200-400 mesh; resin lower loading: 1.0-1.5 mmol/g of $\mathrm{Cl}^{-}$and resin higher loading: 3.0-3.5 mmol/g of $\mathrm{Cl}^{-}$), polyethylenimine (low molecular weight typical $\mathrm{M}_{\mathrm{w}}-800$ ), chitosan (low molecular weigh, 75-85\% deacetylated), poly(sodium 4-styrene-sulfonate typical $\mathrm{M}_{\mathrm{w}}$ 70,000), poly(ethyleneglycol)methyl ether 2000, ionic change resin IRA400 Amberlite PSDV-NH (Poly(styrene co-divivylbenzene)aminomethylated 1\% crosslink 70-90 mesh) were obtained from Aldrich and used without further purification. 4,4'-diaminobiphenyl was obtained from Fluka. Porphyrin $\mathbf{P}_{\mathbf{1}}$ and $\mathbf{T D C P P H} \mathbf{H}_{\mathbf{2}}$ were prepared according to previously reported procedures. ${ }^{10,31}$

\section{Instrumentation}

${ }^{1} \mathrm{H}$ NMR spectra were recorded on a $300 \mathrm{MHz}$ Bruker-AMX spectrometer. $J$ values are given in Hertz. Mass spectra were obtained on a HP 5973 MSD apparatus by electronic impact at $70 \mathrm{eV}$. Elemental analysis was carried out using a Fisons Instruments EA1108CHNS-0 apparatus. Absorption spectra were measured on a Hitachi U-2001 spectrometer and Ocean Optics USB spectrometer. Gas chromatography was carried out using a Supelcowax (30 m, $0.25 \mathrm{~mm}$ ) capillary column on a Hewlett-Packard 5890A instrument with a Hewlett-Packard 3396A integrator. GC analysis was run at $80{ }^{\circ} \mathrm{C}(5 \mathrm{~min}) / 20{ }^{\circ} \mathrm{C}$ $\min ^{-1} / 200{ }^{\circ} \mathrm{C}$ (20 min); detector temperature $250{ }^{\circ} \mathrm{C}$, injector temperature $220{ }^{\circ} \mathrm{C}$. Light intensity was measured with a X97 radiometer from Gigahertz-Optik.

\section{Synthesis of supported porphyrins and Merrifield polymer linked to 4,4'- diaminobiphenyl}

SPS-1 $(0.040 \mathrm{mmol} / \mathrm{g})$ and SPS-2 $(0.21 \mathrm{mmol} / \mathrm{g})$ were prepared as described. ${ }^{10,14}$

\section{Synthesis of SPS-3}

To a stirred solution of $80 \mathrm{ml}$ dry toluene containing $3.0 \mathrm{mmol}$ of 1,12-diaminododecane, $1.0 \mathrm{mmol}$ of (3-glycidyloxypropyl)-trimethoxysilane was added. The resulting mixture was allowed to react at $80{ }^{\circ} \mathrm{C}$ for $24 \mathrm{~h}$. To this solution $1.5 \mathrm{~g}$ of activated $\mathrm{SiO}_{2}$ and $5 \mathrm{ml}$ of EtOH were added and the stirred solution was maintained at $80{ }^{\circ} \mathrm{C}$ for $24 \mathrm{~h}$. The amino functionalized silica was isolated by filtration and washed with $\mathrm{MeOH}$ and $\mathrm{EtOH}$. Then, 
it was refluxed with EtOH during $1 \mathrm{~h}$, then filtrated again and dried at $40{ }^{\circ} \mathrm{C}$ for several days. Elemental analysis showed a nitrogen content of $0.87 \%$. This aminoalkylated silica derivative (Silica- $\mathrm{NH}_{2}$ ) $\left(380 \mathrm{mg}\right.$ ) was reacted with the chlorosulfonyl derivative $\mathbf{P}_{2}$ as described for SPS-1. ${ }^{10}$ Elemental analysis showed a nitrogen content of $1.52 \%$, which corresponds to a porphyrin loading of $0.12 \mathrm{mmol} / \mathrm{g}$.

\section{Synthesis of SPS-4}

The procedure is similar to that used for SPS-1. First the aminoalkylated Merrifield polymer was prepared by mixing $3.0 \mathrm{~g}$ of Merrifield polymer (higher loading) in $25 \mathrm{~mL}$ of DMF, $1.5 \mathrm{~g}$ of 1,12-diaminododecane and keeping the mixture at $70^{\circ} \mathrm{C}$ for $24 \mathrm{~h}$. After cooling, the mixture was poured into $150 \mathrm{~mL}$ of water, filtered, and washed with water, methanol, dichloromethane, and methanol again. The residue was dried in an oven under vacuum. Elemental analysis of this product gives a nitrogen content of $2.64 \%$. This aminoalkylated polymer $(380 \mathrm{mg})$ was made to react with the chlorosulfonyl derivative $\mathbf{P}_{2}$ as described for SPS-1. Elemental analysis showed a nitrogen content of 3.24\%, which corresponds to a porphyrin loading of $0.11 \mathrm{mmol} / \mathrm{g}$.

\section{Synthesis of SPS-5}

At room temperature, $15 \mathrm{~mL}$ of chlorosulfonic acid was added to $213 \mathrm{mg}$ of porphyrin $\mathbf{P}_{1}$. The solution was stirred for $2 \mathrm{~h}$ and then carefully poured onto ice in order to precipitate the porphyrins. The precipitate was filtered, dried, dissolved in dichloromethane, and the solution dried with sodium sulfate. The solution was concentrated to $30 \mathrm{~mL}, 1 \mathrm{~mL}$ of pyridine was added followed by $300 \mathrm{mg}$ of PSDV-NH $\mathrm{N}_{2}$. The mixture was stirred for 2 days at $30^{\circ} \mathrm{C}$, filtered, and washed with dichloromethane, tetrahydrofuran, methanol, and dichloromethane again. Non-bonded porphyrin was eliminated with these washings. After drying the solid under vacuum, elemental analysis showed a nitrogen content of $2.0 \%$, which corresponds to a porphyrin loading of 0.22 $\mathrm{mmol} / \mathrm{g}$.

\section{Synthesis of Merrifield polymer linked to 4,4'-diaminobiphenyl}

To a mixture of $3.0 \mathrm{~g}$ of Merrifield polymer (lower loading) in $25 \mathrm{~mL}$ of DMF, $1.5 \mathrm{~g}$ of 4,4'- diaminobiphenyl was added. The mixture was placed at room temperature for $24 \mathrm{~h}$. After this time, the mixture was poured in $150 \mathrm{~mL}$ of water, filtered, and washed with water, methanol, dichloromethane, and methanol again. The residue was dried in an oven under vacuum. Elemental analysis showed a nitrogen content of $1.18 \%$.

\section{Photosynthetic oxidation experiments. General photooxidation procedure}

Photooxidation experiments were carried out at room temperature using a laboratory-built photoreactor consisting of three $50 \mathrm{~W}$ lamps. The reactions were carried out in a flask equipped with a water condenser and an inlet for air. The solutions were irradiated with a 
stream of air continuously flowing into the flask. The substrate ( $\alpha$-terpinene, $4.9 \mathrm{mmol}$ ) in $65 \mathrm{~mL}$ of chloroform was mixed with the appropriate amount of photosensitizer $\left(9.8 \times 10^{-4} \mathrm{mmol}\right.$ of porphyrin or the equivalent molar amount of supported porphyrin) to produce a 1/5000 molar ratio of sensitizer to substrate, and $203 \mathrm{mg}$ of sodium hydrogen carbonate was added. The progress of the reaction was monitored by monitoring the disappearance of the reagent by GC. The photosensitizer was collected by filtration, and the product was obtained by evaporation of the solvent and analysed by ${ }^{1} \mathrm{H}$ NMR measurements. ${ }^{32,33}$

\section{Photokinetic oxidation experiments. General procedure}

The experiments were carried out at room temperature using a laboratory-built photoreactor consisting of one $50 \mathrm{~W}$ lamp equipped with water filter (radiation intensity $0.75 \mathrm{~mW} / \mathrm{cm}^{2}$ ). The reactions were carried out in a quartz cell equipped with a magnetic stirrer and an air inlet. The solutions were irradiated with a stream of air continuously flowing into the cell.

\section{Experiments of photooxidation of 9,10-dimethylanthracene (DMA) with TDCPPH} $1.5 \mathrm{ml}$ of DMA solution $\left(1 \times 10^{-4} \mathrm{M}\right)$ was mixed with $0.5 \mathrm{ml}$ of a solution of $\mathrm{TDCPPH}_{2}$ $\left(2 \times 10^{-5} \mathrm{M}\right), 1 \mathrm{ml}$ of chloroform. The progress of the reaction was monitored by UV-vis spectroscopy at $380 \mathrm{~nm}$ by the disappearance of the DMA absorbance.

\section{Photooxidation experiments of DMA with supported photosensitizers (Figure 1 and table 2)}

$1.5 \mathrm{ml}$ of DMA solution $\left(1 \times 10^{-4} \mathrm{M}\right)$ was mixed with $1.5 \mathrm{ml}$ of chloroform and the appropriate amount of supporting photosensitizer, taking into account the respective loading. The mixture was kept with stirring in the dark for $15 \mathrm{~min}$. Then, the mixture was irradiated and the progress of the reaction was monitored by UV-vis spectroscopy at 380 $\mathrm{nm}$, by the disappearance of DMA absorbance.

Photooxidation experiments of DMA with $\mathrm{TDCPPH}_{2}$ (as sensitizer) in presence of bulk polymers (Table 3 )

$1.5 \mathrm{ml}$ of DMA solution $\left(1 \times 10^{-4} \mathrm{M}\right)$ was mixed with $0.5 \mathrm{ml}$ of a solution of $\mathrm{TDCPPH}_{2}$ $\left(2 \times 10^{-5} \mathrm{M}\right), 1 \mathrm{ml}$ of chloroform and $1 \mathrm{mg}$ of different polymers. The mixture was kept in the dark for $1 \mathrm{~min}$. Then, the mixture was irradiated and the progress of the reaction was monitored by UV-vis spectroscopy at $380 \mathrm{~nm}$ by disappearance of DMA absorbance. 


\section{Acknowledgements}

The authors thank Chymiotechnon, FCT-POCTI/QUI/55931/2004 and FCT (SFRH/BD/40228/2007) for financial support. NMR data were obtained at the Nuclear Magnetic Resonance Laboratory of the Coimbra Chemistry Centre (www.nmrccc.uc.pt), Universidade de Coimbra, supported in part by grant REEQ/481/QUI/2006 from FCT, POCI-2010 and FEDER, Portugal

\section{References}

1. DeRosa, M. C.; Crutchley, R. J. Coord. Chem. Rev. 2002, 233, 351.

2. Clennan, E. L.; Pace, A. Tetrahedron 2005, 61, 6665.

3. Balci, M. Chem. Rev. 1981, 81, 91.

4. Griesbeck, A. G.; Bartoschek, A.; El-Idreesy, T. T. E.; Hoinck, O.; Miara, C. J. Mol. Catal. A: Chem. 2006, 251, 41.

5. Prein, M.; Adam, W. Angew. Chem. Int. Ed. 1996, 35, 477.

6. Alberti, M. N.; Orfanopoulos, M. Tetrahedron 2006, 62, 10660.

7. Wahlen, J.; De Vos, D. E.; Jacobs, P. A.; Alsters, P. L. Adv. Synth. Catal. 2004, 346, 152.

8. Benaglia, M.; Danelli, T.; Fabris, F.; Sperandio, D.; Pozzi, G. Org. Lett. 2002, 4, 4229.

9. Griesbeck, A. G.; El-Idreesy, T. T.; Bartoschek, A. Adv. Synth. Catal. 2004, 346, 245.

10. Ribeiro, S. M.; Serra, A. C.; Rocha Gonsalves, A. M. d. A. Tetrahedron 2007, 63, 7885.

11. Gollnick, K. Adv. Photochem. 1968, 6, 1.

12. Azenha, E. G.; Serra, A. C.; Pineiro, M.; Pereira, M. M.; Seixas de Melo, J. S.; Arnaut, L. G.; Formosinho, S. J.; Rocha Gonsalves, A. M. d. A. Chem. Phys. 2002, 280, 177.

13. Murtinho, D.; Pineiro, M.; Pereira, M. M.; Gonsalves, A. M. d. A. R.; Arnaut, L. G.; Graça Miguel, M.; Burrows, H. D. J. Chem. Soc., Perkin Trans. 22000.

14. Ribeiro, S. M.; Serra, A. C.; Rocha Gonsalves, A. M. d. A. J. Catal. 2008, 256, 331.

15. Zois, D.; Vartzouma, C.; Deligiannakis, Y.; Hadjiliadis, N.; Casella, L.; Monzani, E.; Louloudi, M. J. Mol. Catal. A: Chem. 2007, 261, 306.

16. Thomas, D. W.; Martell, A. E. J. Am. Chem. Soc. 1956, 78, 1338.

17. Inbaraj, J. J.; Vinodu, M. V.; Gandhidasan, R.; Murugesan, R.; Padmanabhan, M. J. Appl. Polym. Sci. 2003, 89, 3925.

18. 1Vinodu, M. V.; Padmanabhan, M. J. Polym. Sci. A 2001, 39, 326.

19. Bourdelande, J. L.; Karzazi, M.; Dicelio, L. E.; Litter, M. I.; Tura, G. M.; Román, E. S.; Vinent, V. J. Photochem. Photobiol. A: Chem. 1997, 108, 273. 
20. Lu, K. K.; Thomas, J. K. J. Photochem. Photobiol. A: Chem. 1993, 71, 55.

21. Schaap, A. P.; Thayer, A. L.; Blossey, E. C.; Neckers, D. C. J. Am. Chem. Soc. 1975, 97, 3741.

22. Julliard, M., Immobilized Photosensitizers and Photocatalysis. In Homogeneous Photocatalysis, Chanon, M., Ed. Wiley: New York, 1997; p 221.

23. Clough, R. L.; Dillon, M. P.; Iu, K.-K.; Ogilby, P. R. Macromolecules 1989, 22, 3620.

24. Schiller, K.; Müller, F. W. Polym. Int. 1991, 25, 19.

25. Gerdes, R.; Bartels, O.; Schneider, G.; Wohrle, D.; Schulz-Ekloff, G. Polym. Adv. Technol. 2001, 12, 152.

26. Nowakowska, M.; Kepczynski, M. J. Photochem. Photobiol. A. Chem. 1998, 116, 251.

27. Bonnett, R.; Krysteva, M. A.; Lalov, I. G.; Artarsky, S. V. Water Res 2006, 40, 1269.

28. Clennan, E. L.; Chen, M. F. J. Org. Chem. 1995, 60, 6004.

29. Schweitzer, C.; Schmidt, R. Chem. Rev. 2003, 103, 1685.

30. Perrin, D. D.; Armarego, W. L. F., Purification of Laboratory Chemicals. 3rd ed.; Pergamon Press: U. K., 1988.

31. Johnstone, R. A. W.; Nunes, M. L. P. G.; Pereira, M. M.; Rocha Gonsalves, A. M. d. A.; Serra, A. C. Heterocycles 1996, 43, 1423.

32. Tokuyama, H.; Nakamura, E. J. Org. Chem. 1994, 59, 113.

33. Pouchert, C. J., The Aldrich Library of NMR Spectra. 2nd Ed.; Aldrich Chemical: Millwaukee WI, 1983; Vol. 1, pp 742. 